\title{
The Impact of the Transition to Outcomes-Based Teaching on University Preparedness in Mathematics in South Africa
}

\author{
Johann Engelbrecht and Ansie Harding \\ University of Pretoria
}

\begin{abstract}
Following the political changes of 1994 in South Africa, the decision was taken to replace the traditional skills-based education system at primary and secondary school level (Grades 1-12) with an outcomes-based education system (OBE). The implementation of the OBE system did not come without problems, giving rise to revised initiatives. The OBE approach, referred to as Curriculum 2005, was introduced into schools in 1998, for all learners in Grades 1- 6 and progressively phased in after that. In 2002, the OBE system was put on hold for the two upper grades of these learners. Learners in these two grades reverted back to skills-based learning for their last three years of schooling, i.e. in Grades $10-12$. The most senior of these learners that had been subjected to four years of OBE and another three years of the old system finished their schooling in 2005 and 2006 and entered university in 2006 and 2007. These groups are of interest. Students ahead of them had their full schooling in the old system and students two years younger were only subjected to OBE. These students are the "group in the middle". This paper reports on what the impact is of the growing pains of such a new, inadequately planned education system on the mathematics preparedness of students entering university. This report will be extended in 2009 when the learners that have been fully subjected to the OBE system enter university.
\end{abstract}

\section{Introduction}

Current global markets require that all educated citizens become science-andmath-literate (Seymore, 2001). In South Africa this requirement is recognised by the fact that the newly implemented outcomes-based education (OBE) education system requires of all students to do a mathematics subject up to Grade 12. This change is one of many brought about by implementation of the South African OBE system. The OBE system, first implemented in 1998, not only involves a change in approach but also a change in curriculum. In other words, the OBE system demands changes at the heart of the education system. The transition to the OBE system has been fraught with criticism (e.g. Jansen, 1998) and necessitated revisions and modifications along the way, discussed in a later section. The question addressed in this paper is how such a radical change affects the mathematical preparedness of students entering university. In addition, there are other factors impacting on the mathematical preparedness of students for university that also need to be taken into account, discussed subsequently.

\section{Mathematical Preparedness}

A century ago, students enrolling for a university mathematics course tended to fit a particular profile. University lecturers in mathematics could assume that all students had certain skills and classes tended to be small (Craig, 2007; Zevenbergen, 2001). This situation has gradually been changing, with a greater number of students enrolling for courses, and those students having more diverse backgrounds. Diversity can include language, culture and academic preparedness. 
Lecturers teaching first year mathematics, whether as a main subject, or as a service course, face a problem deciding where to start, and what background knowledge and skills can be assumed (Cox, 2000).

The concern at tertiary level that students are not meeting the expectations of preparedness met by their predecessors is noted by several authors. Hoyles, Newman and Noss (2001), as well as Craig (2007), cite a variety of studies expressing concern about the mismatch between university expectations and the wide range of mathematical skills levels of new students. Wood (2001) describes the necessity for academic structures such as bridging courses for students that return to academic life after substantial absence.

Reasons for the perceived changes include increased enrolment numbers (Northedge, 2003; Seymore, 2001; Wood, 2001) and changing school curricula (De La Paz, 2005; Hoyles et al., 2001). It is the latter type of change combined with a change in teaching and learning approaches that we focus on in this study. Disparity in levels of mathematical preparedness creates challenges to lecturers and results in, for example, the development of bridging courses and academic support programmes, changes in curriculum and changes in assessment strategies (Craig, 2007; Northedge, 2003; Wood, 2001).

\section{The South African Situation}

After the change in government in 1994, an interim curriculum was introduced for all grades in primary and secondary schools in South Africa and which was essentially an edited version of the 1983 national curriculum so that all learners in SA were offered the same grade 12 examination, irrespective of which education department their school was in.

Up until 1997 the traditional way of teaching, based on an educator-centred approach, was used in South African schools (Jacobs, Gawe \& Vikalisa, 2000; Lichakane, 2005). The perception was that learners sat passively listening to the educator taking notes and not actively participating in the learning process. The Department of Education realised that many learners participating in the school system were not acquiring problem-solving or critical thinking skills (Department of Education, 2000). In 1997, the then minister of Education, Sibusiso Bengu, announced the implementation of the new outcomes-based education system, called Curriculum 2005 (C2005), which was implemented in 1998 for grades 1, 2 and 3 learners, in 1999 for grades 4, 5 and 6 learners, in 2000 for grade 7, in 2001 for grade 8 and in 2002 for grade 9 learners. The intention was to introduce this curriculum for grade 10 learners in 2003, for grade 11 learners in 2004 and for grade 12 learners in 2005 (this was the origin for the name Curriculum 2005), but the curricula for these grades were not developed in time for implementation. Research also indicated some problems with the new curriculum and C2005 was reworked into the Revised National Curriculum Statement (RCNS), which was (or will be) introduced into grades 1,2 and 3 in 2004, 4, 5 and 6 in 2005, into grade 7 and 10 in 2006, 8 and 11 in 2007 and 9 and 12 in 2008.

The mentioned interruption in the schedule of introducing OBE into South African schools had as consequence the reality that three groups of learners (learners that were or would be in grade 12 in 2005, 2006 or in 2007) had been subjected to this new approach in the education system for 5 or 6 years and were then moved back to the old curriculum for their last three years of secondary school. In 2006 universities in the country received the first products of the OBE approach-learners that have had partial exposure to OBE. This partial exposure 
is also true for the groups of students that finish(ed) secondary school in 2006 and 2007 and who enter university in 2007 and in 2008. Since the conventional system and the OBE approach differs significantly with respect to teaching and learning approaches as well as content, it was anticipated that these three groups of students might have suffered being moved to OBE at first and then back to the old system again after a number of years. Learners that finish secondary school in 2008 will be the first group of students that have had full exposure to OBE over their entire school career. These students will enter university in 2009.

\section{The Vision of $O B E$}

The new vision for education was to integrate education and training into a system of lifelong learning. OBE was adopted as the approach that would enable the articulation between education and training, recognition of prior learning, and thus increased mobility for learners between different vocations (Graven, 2002). OBE was introduced to address the imbalance in education (due to the political dispensation) and the changing demands in the market place arising from the need for a more skills-based workforce. Quoting Bengu (1997), OBE

...aims at equipping learners with the knowledge, competencies and orientations needed for success after they leave school...Its guiding vision is that of thinking, competent future citizens...that the new curriculum will integrate education and training incorporating a view of learning which rejects a rigid division between academic and applied knowledge and skills....and foster learning which encompasses a culture of human rights, multi-lingualism and multi-culturalism. (p. 1)

The key principles on which Curriculum 2005 is based are: integration; holistic development; relevance; participation and ownership; accountability and transparency; learner-orientation; flexibility; critical and creative thinking; progression; anti-biased approach; inclusion of learners with special education needs; quality standards; and international comparability (Department of Education, 1997).

In the OBE pedagogy, learners work collaboratively posing questions, arriving at and formulating conjectures and discussing the validity of solutions (Lichakane, 2005). According to Owen (1995) the educator's role is to promote discourse in which learners listen to, respond to, and question the educator and one another and try to convince themselves and one another of the validity of particular representations, solutions, conjectures, and answers.

Curriculum 2005 is premised on a learner-centred, outcomes-based approach to education. A distinguishing feature of Curriculum 2005 is its explicit political agenda. Curriculum 2005 is a vehicle for restructuring South African society along democratic principles (Graven, 2002). This role is captured in the introduction to the Curriculum 2005:

The curriculum is at the heart of the education and training system. In the past the curriculum has perpetuated race, class, gender and ethnic divisions and has emphasised separateness, rather than common citizenship and nationhood. It is therefore imperative that the curriculum be restructured to reflect the values and principles of our new democratic society. (Department of Education, 1997, p. 2)

Educators are the key contributors to the transformation of education in South Africa. They should be mediators of learning, interpreters and designers of learning programmes and materials, leaders, administrators and managers, 
scholars, researchers and lifelong learners, community members, assessors and specialists (Lichakane, 2005; Revised National Curriculum Statement, 2002).

In this transition to OBE, Graven (2002) identifies three major shifts in the philosophy of mathematics and mathematics education, relating to the approach to mathematics teaching, the nature and contents of mathematics, and the role of mathematics education.

The Kentucky Department of Education (1995) gives the following comparison between the traditional approach and a standards-based approach (the USA equivalent of an outcomes-based approach) (see Table 1).

Table 1

Comparison of Traditional and Standards-Based Education

\begin{tabular}{ll}
\hline Traditional Approach & Standards-Based Approach \\
\hline Calendar-driven instruction: School & Standards-driven instruction: Success \\
structured by calendar, e.g., age & based on performance
\end{tabular}

grouping, scheduling, etc

Constrained opportunities: Limited Expanded opportunities: Teaching time instructional strategies, physical environment, time determined by learning and curriculum

Cumulative achievement: Work on discrete skills in predetermined time frames

Competitive learning: Individual environment with competition

Comparative evaluation: Based on relative performance of other students needs

Culminating achievement: Culminating achievement at the end of a learning cycle

Cooperative learning: Cooperative environment with self-directed challenges

Criterion evaluation: Based on set standards of quality

Curriculum coverage: Exact knowledge Instructional coaching: Finding dissemination within a predetermined timeframe instructional tools to enable students to demonstrate standards given appropriate time

Segmented content: Discrete skills with few connections

Connected content: Integration within and between disciplines, connectedness

Curriculum design: Focus on segmented coverage Design down: Focus on culminating performances

Adapted from Kentucky Department of Education (1995), p. 9.

Graven (2002) is of the opinion that implementing the new curriculum should not simply involve replacing old practice with new practice, but that the new curriculum should be fashioned in such a way that it becomes part of the teacher's way of being. She identifies four new roles of teachers:

- to support learners to critically analyse the way mathematics is used socially, politically, and economically to prepare them for democratic citizenship.

- to bring mathematics from outside into the classroom.

- to apprentice learners into ways of investigating mathematics being a person who has an interest in pursuing mathematics for its own sake. 
- to convey the practices of the broader community of mathematics teachers.

\section{The Objective of the Project}

The objective of this project is to determine the impact of the OBE approach on university preparedness in mathematics. The transition groups, mentioned above, are first year students in 2007 and 2008. Because of their partial exposure to OBE these groups of students differ from the students that entered university before 2007 and are also different from the groups of students that will enter university from 2009 onwards. Groups before 2007 had no OBE exposure while students from 2009 onwards will have had full OBE exposure since 1998.

In this paper, the first stage of the project, we investigate the university preparedness of the transition groups. In a follow up paper the preparedness of students that will have had full exposure to OBE will be investigated.

\section{The Measuring Instrument}

As a measuring instrument we used the mathematics achievement test developed as part of the Alternative Admissions Research Project (AARP), a project initiated at the University of Cape Town (AARP; Haeck, Yeld, Conradie, Robertson, \& Shall, 1997). The University of Pretoria has been collaborating in developing these tests. An English language based academic skills test and, where appropriate, two mathematics tests (an achievement test and a comprehension test) and a scientific reasoning test, are the main AARP instruments used in recommending students for admission to the university.

These tests have been set up to provide an access route for applicants whose final school results might not portray their full potential. Students with good Grade 12 results are not disadvantaged in any way by writing the tests. All firsttime entering undergraduate applicants are invited to write the tests at one of the various testing centres around the country. Students write these tests either in the year before entering university or in the beginning of their first year, before lectures start. These tests have been used by a number of institutions around the country.

All first-time entrant applicants to the university (who have not had any tertiary education) are eligible to take the tests and wherever appropriate and possible, recommendations are coupled to placement decisions. The AARP tests aim to identify talented students who are not identifiable on the basis of their matriculation results, or who did not attend schools which provide reliable pregrade 12 examination performance data: it does not compete with the matriculation score.

The mathematics achievement test has been designed to determine the level of mathematical competency of students. The achievement test, comprising 31 multiple-choice items that cover topics usually included in the school syllabus, relies heavily on prior mathematical knowledge and skills. Candidates are allowed 90 minutes to complete the test. Candidates have to show that they can perform basic mathematical computations and manipulations and that they can solve problems. Results in the achievement test also play a role in determining whether a student needs further educational intervention in order for him/her to be successful in tertiary mathematics.

The mathematics comprehension test has been designed to minimise the effect 
of prior learning in mathematics, thereby enabling all students to demonstrate their ability to learn and apply mathematical knowledge. This goal is achieved firstly by using topics that fall outside the scope of the school syllabus and therefore are unlikely to have been taught in a formal setting, and secondly by using text that serves as a guide to answering questions scaled in complexity. However, comprehension tests results have no bearing on this study.

\section{Research Design}

The sample population for this study consisted of the students that registered at the University of Pretoria for the first time over the last three years 2005-2007 and who also wrote the mathematics achievement test. We analysed the results of these students, which numbered 2040 in 2005, 2176 in 2006 and 2005 in 2007.

The mathematics achievement test has been virtually identical over the last three years, which makes it appropriate to compare results of the different groups. Questions in the test have been grouped into 12 categories of topics by the authors. The topics are:

- Percentages

- Number concept, manipulation

- Modelling, word sums

- Ratio and proportion

- Algebraic manipulation

- Exponents

- Functions

- Graphs

- Geometry

- Trigonometry

- $\quad$ Logical thinking

- $\quad$ Spatial thinking

(Some items were grouped in more than one category.)

Students' average scores for the questions in each of the topics were calculated and the respective results for the years 2005-2007 were compared per category and in total. The mean student performances in each topic for the three years were then statistically compared, using an ANOVA test for three sets of data. Where significant differences occurred the mean student performances in each topic for the three pairs of years, 2005 vs 2006, 20005 vs 2007 and 2006 vs 2007 were compared using a $t$-test in order to narrow the difference down to a particular pair of years.

\section{Results}

Mean student performances (percentages) for each of the twelve topics for the years $2005-2007$ are given numerically in Table 2 and graphically in Figure 1. From the data in Table 2 it seems as if there is a slight improvement in the overall test performance from 2005 to 2006, and again to 2007. A further tentative observation is that student performance was particularly poor in the four topics of percentages, modelling and word sums, ratio and proportion and trigonometry. Students performed best in the four topics of number concept, algebraic manipulation, functions and graphs. 
Table 2

Mean student performances (\%) in the different topics

\begin{tabular}{lllll}
\hline & & $\mathbf{2 0 0 5}$ & $\mathbf{2 0 0 6}$ & $\mathbf{2 0 0 7}$ \\
\hline Number of students & $\begin{array}{l}\text { Number } \\
\text { of items }\end{array}$ & Mean student performance \\
Topic & 2040 & 2176 & 2005 \\
Percentages & 2 & 21.3 & 26.1 & 26.3 \\
Number concept, manipulation & 3 & 56.0 & 54.8 & 54.5 \\
Modelling, word sums & 3 & 28.3 & 28.7 & 19.9 \\
Ratio and proportion & 3 & 31.1 & 30.6 & 24.1 \\
Algebraic manipulation & 6 & 48.2 & 48.6 & 48.9 \\
Exponents & 3 & 40.0 & 43.8 & 43.8 \\
Functions & 3 & 51.5 & 52.5 & 53.8 \\
Graphs & 4 & 51.3 & 54.8 & 56.6 \\
Geometry & 5 & 31.3 & 35.1 & 47.0 \\
Trigonometry & 3 & 32.9 & 29.1 & 30.2 \\
Logical thinking & 3 & 41.2 & 41.2 & 43.4 \\
Spatial thinking & 3 & 46.7 & 46.4 & 47.3 \\
& & & & \\
Total test mark & & 43.1 & 44.2 & 44.7 \\
\hline
\end{tabular}

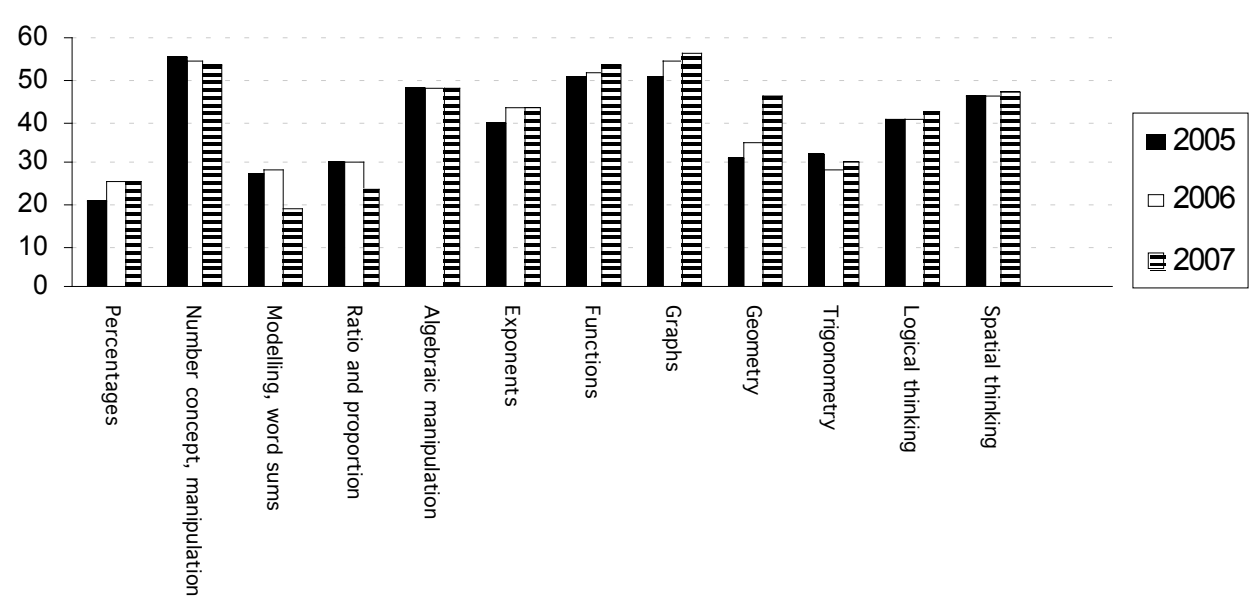

Figure 1. Mean student performances (\%) in the different topics.

The conclusion that students are more skilled in the latter topics is, however, somewhat risky because the questions used for these topics could have been perceived as easier than questions in other topics by students. The purpose of this investigation was not to compare performance in the different topics but to 
compare performance in same topic between different years.

Results of the ANOVA test for mean student performances for the three sets of data in each of the twelve topics are given in Table 3. Overall improvement in the test was statistically significant although percentage-wise this improvement was small.

Table 3

ANOVA Test Results for the Comparison of Student Performance in the Twelve Topics

\begin{tabular}{lc}
\hline Topic & $p$-value \\
\hline Percentages & 0.0000006 \\
Number concept, manipulation & 0.1395572 \\
Modelling, word sums & 0.0000000 \\
Ratio and proportion & 0.0000000 \\
Algebraic manipulation & 0.6556436 \\
Exponents & 0.0002027 \\
Functions & 0.0586641 \\
Graphs & 0.0000000 \\
Geometry & 0.0000000 \\
Trigonometry & 0.0001762 \\
Logical thinking & 0.0251472 \\
Spatial thinking & 0.5902861 \\
& \\
Total test mark & 0.0000010 \\
\hline
\end{tabular}

From the calculated $p$-values it is clear that statistically significant differences in averages (at the 1\% significance level) exist in seven of the twelve topics, and to find out where these differences lie we performed $t$-tests between the three pairs of years, respectively, for these seven topics. The $p$-values for the relevant $t$-tests are given in Table 4.

Table 4

t-test $p$-values for the Different Topics Between the Three Pairs of Years

\begin{tabular}{lccc}
\hline Topic & $2005 / 2006$ & $2005 / 2007$ & $2006 / 2007$ \\
\hline Percentages & 0.000003 & 0.000002 & 0.007947 \\
Modelling, word sums & 0.561157 & 0.000000 & 0.000000 \\
Ratio and proportion & 0.571155 & 0.000000 & 0.000001 \\
Exponents & 0.000279 & 0.000482 & 0.416872 \\
Graphs & 0.000077 & 0.000000 & 0.283293 \\
Geometry & 0.000000 & 0.000000 & 0.000000 \\
Trigonometry & 0.000059 & 0.005175 & 0.022185 \\
& & & \\
Total test mark & 0.060317 & 0.004944 & 0.004934 \\
\hline
\end{tabular}


From these tables it is clear that statistically significant differences (at the $1 \%$ significance level) in student performance occurred in the following topics:

- $\quad$ Percentages - an improvement from 2005 to 2006 and again to 2007.

- Modelling and word sums - no change from 2005 to 2006 but then a decline in 2007.

- Ratio and proportion - no change from 2005 to 2006 but then a decline in 2007.

- Exponents - an improvement from 2005 to 2006 and then no significant change from 2006 to 2007.

- Graphs - a improvement from 2005 to 2006 and then no significant change from 2006 to 2007.

- Geometry - an improvement from 2005 to 2006 and again from 2006 to 2007.

- Trigonometry - an improvement from 2005 to 2006 and then no significant change to 2007.

For the test as a whole the improvement in student performance was not significant from 2005 to 2006 but it did improve significantly to 2007, although percentage-wise this improvement was small.

\section{Discussion}

A first observation, although not totally directed towards the study, is that student performance from 2005 to 2006 has largely been maintained or improved. Given the circumstances of political turmoil and extreme changes within a society that is recovering from historical disadvantages, this can be considered a positive result.

The aim of this study, however, was to investigate the impact of the limited exposure to the OBE system on the 2006 and 2007 intake of students, the first of such students. The fact that these students reverted back to the old system for the last few years of their schooling adds intrigue to the study. The data provides clear-cut differences in three distinct areas between the 2007 students and those of the previous two years. These differences are visually obvious from the graphical presentation and statistically verified. The areas are:

- Modelling and word sums

- Ratio and proportion

- Geometry

In the first two areas a significant and consequential decline was observed and in the last area an equally striking increase was observed. The fact that the sample consisted of more than 2000 students, all of university calibre, makes these observations too notable to ignore and warrants closer scrutiny.

\section{Modelling and Word Sums}

Giving mathematical meaning to problems posed in words epitomises the ideals of the outcomes-based education. "Its guiding vision is that of thinking, competent future citizens... a view of learning that rejects a rigid division between academic and applied knowledge and skills." (Bengu, 1997, p. 1). Modelling and word sums require of the learner to make sense of the surrounding world and this is the areas where the biggest drop occurred - from an already low mean 
performance of just over 28\% in 2005/ 2006 to less than $20 \%$ in 2007.

Examples of questions are (examples are similar but not identical to questions in the instrument for security purposes as these instruments are still being used)

- Tap A fills a drum in 1 hour. Tap A and tap B together are able to fill the drum in 20 minutes. How long will it take tap $B$ alone to fill the drum?

- Three girls share a certain amount of money in the ratio 1:2:3. If the first two girls' shares add up to R900, how much money does the third girl get?

These questions are not easy to do in general and most educators will attest to difficulties experienced by students when doing this type of problem, which could explain the low performance in general, but not the sudden drop for the 2007 intake. To point the finger immediately at the OBE system would be rash. There are too many other factors to consider-there were many teething problems with the initial implementation of the OBE system, educators were neither prepared nor assisted and no textbooks were available. Furthermore, one cannot discard the fact that these students started off in one system and reverted back to another system and could now be suffering the consequences of a confused education.

\section{Ratio and Proportion}

Questions in this category are closely linked to modelling and word sums as the third example question above and the second example below show. Other survey questions are similar to:

- The table shows values of $m$ and $n$, where $m$ is directly proportional to $n$. What is the value of $r$ ?

\begin{tabular}{lll}
\hline$m$ & 9 & 21 \\
\hline$n$ & 12 & $r$
\end{tabular}

- If $x$ jackets cost $r$ cents, what is the cost (in rand) of $y$ jackets?

Although not quite as dramatic there is still a surprisingly large drop in performance of the 2007 student intake from close to $31 \%$ in $2005 / 2006$ to just over $24 \%$ in 2007. The mathematics required here entails very little algebraic manipulation and is more conceptual in nature, and this conceptual understanding seems to be the stumbling block. This view is supported by the steady performance in the algebraic manipulation category of around 48\% right through. It is disturbing that there is a decrease in conceptual understanding. Such a decrease would have serious implications for university mathematical learning where there is an emphasis on conceptual understanding. Yet one should again keep in mind that the 2007 intake is part of an exceptional group of students and a premise such that there is a decrease in conceptual understanding brought about by the OBE system could only be confirmed or denied when the performance of the 2009 student intake and subsequently are investigated.

\section{Geometry}

The increase in performance of the 2007 intake (47\% compared to just over $31 \%$ in 2005 and 35\% in 2006) is pleasantly surprising. Questions included:

- Calculating angles from a diagram showing a line intersecting two other parallel lines. 
- Calculating the diagonal of a rectangular prism with given sides.

Measurement and representation of shape and space, time and motion figure prominently in mathematics outcomes of the OBE system. Shape and space translate to geometry and it is pleasing to observe that even for the exceptional group of 2007 geometrical skills have not only stayed intact but have improved. During the junior years that these students were subjected to OBE they were exposed to an investigative OBE approach in geometry. The nature of geometry lends itself to hands-on investigations, a prominent teaching approach in OBE, especially in junior years. This may have contributed to better understanding of geometrical principles. A further speculative explanation for this observation may be that although the OBE system could affect a change in teaching methods for geometry, the content is so well defined that it should remain unchanged. The robust content would then survive the turmoil of changing to a new system or reverting back to an old system, as was the case.

\section{Conclusion}

The OBE system has suffered, and still is suffering, severe criticism as an inadequate and poorly implemented system (e.g. Jansen, 1998). Yet, as far as university preparedness is concerned, our results do not agree with this dismal portrayal. In all but two topic areas student performances were on par with those in previous years. In the geometry topic students even outperformed their predecessors

However, it is unfortunate that the two areas in which there is a decline in performance are of consequence in tertiary mathematics and for life skills in general. Both mathematical modelling and the topic of ratios and proportion are concepts that are of fundamental importance in university mathematics. An optimistic view as to the cause for the increased performance in geometry and decreased performance in modelling and ratios and proportion would be that this phenomenon is of a transitory nature and that the problem exists because the students under discussion suffered from the confusion of moving to and fro between two systems. Given that these students still followed the old syllabus in their more senior years, yet educators simultaneously tried to incorporate some of the principles of the new system, one cannot but speculate that the disturbed change of educational systems may be to blame.

A less optimistic view is that the (partial) exposure to OBE could be the reason, that the system itself is to blame. Enlightening results in this regard were published by the Department of Education of South Africa (2005) in the 2005 Systemic Evaluation intermediate phase teacher's guide on mathematics. The study was conducted at the Grade 6 level in 2004 in order to provide useful information on learner achievement of important competencies in Mathematics acquired by the OBE approach. Tests were administered to a cross section of Grade 6 learners country wide. Results for the different learning outcomes are presented in Figure 2. 


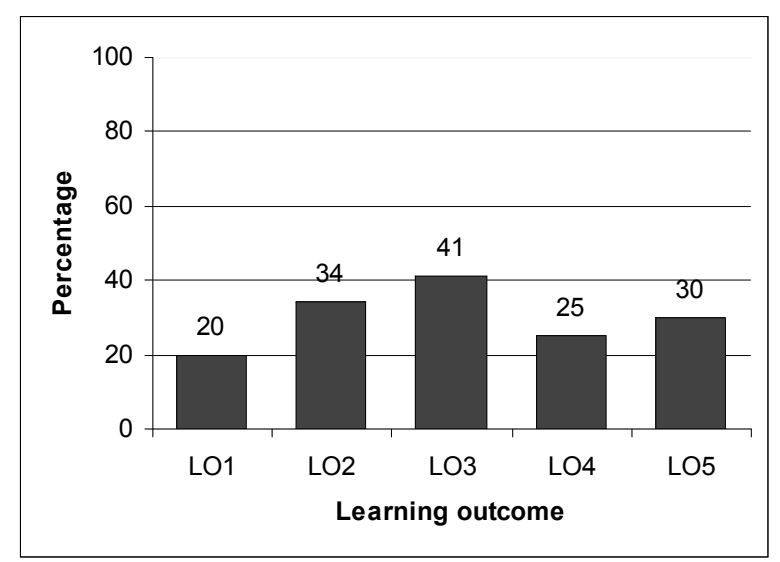

Figure 2. Performance by learning outcome (Department of Education, 2005, p. 37).

The different learning outcomes are:

LO1: Numbers, Operations and Relationships

LO2: Patterns, Functions, Algebra

LO3: Space and Shape

LO4: Measurement

LO5: Data handling

LO3 is geometry at an elementary level and it is performance for this learning outcome that leads (41\%). This result links strongly with our findings. Performance is poorest for $\mathrm{LO} 1(20 \%)$, the learning outcome on numbers, operations and relationships. Questions posed for LO1 show that this is the learning outcome that includes "word sums" and fosters the mathematics that we have categorised as modelling, ratios and proportions. This result also links strongly with our findings. Examples of questions are:

- Write down the ratio of the shaded area to the non-shaded area for the following figure:

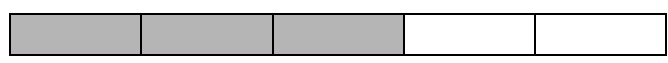

- The times in seconds of the 6 athletes in the $100 \mathrm{~m}$ final for boys are: Charles: 11.90 Zola: 11.23 Tshepo: 11.32 Jabu: 11.09 Conrad: 11.10 Thabo: 11.19

Who came third?

A tentative explanation for the better performance in the geometry outcome LO3 is that this topic lends itself exceedingly to projects and investigations and it is seen as the "fun" topic. Therefore more exposure to this topic is often provided to learners. The poor performance in the number and relationship outcome LO1 could, again tentatively, be explained by the barrier that inadequate language skills set in solving "word problems". English is increasingly the language of instruction and is a second language to most learners. Inadequate English language skills are a concern; a national average of $38 \%$ was achieved in the English equivalent of the 
Systemic Evaluation under discussion.

These results do not bode well for OBE and from our results it seems that the trend is perpetuated to university level. The optimistic view of a transitory problem will be confirmed or denied when the performances of the 2009 intake of students are investigated.

Limitations of the study include that data for this part of the project were collected over three years only. More reliable results may be obtained after more data have been collected. A further limitation is that many teachers may not have been sufficiently prepared to teach using methods indicated by OBE principles. This could have affected the results of this study. This impact is perhaps marginal since the students in this study had limited exposure to OBE.

Another limitation of the study lies in the multiple choice format of the items used in the instrument. Question is whether the items really offer adequate space for investigation of the creative approach that is the main feature of OBE. From this type of question it is almost impossible to find out which solving strategies were used by the solvers-only the results are evaluated.

Although this study was conducted in South Africa, the OBE teaching approach has been and will be deployed in many countries. The South African situation offers an opportunity to study the transition phase with respect to (in our case) university preparedness in mathematics. An international audience should take heed of the implementation hiccups (not discussed in detail in this study), but more importantly of areas that are sensitive to potential fluctuation in performance. Our results tentatively indicate no major disruption in university preparedness.

\section{References}

AARP (Current). Alternative Admissions Research Project. Retrieved July 2007 from http: / / www.ched.uct.ac.za/adp/aarp/

Bengu, S. M. E. (1997). Foreword in Curriculum 2005: Lifelong learning for the $21^{\text {st }}$ century. Pretoria: Department of Education.

Cox, W. (2000). Predicting the mathematical preparedness of first year undergraduates for teaching and learning purposes. International Journal of Mathematics Education in Science and Technology, 31(2), 227- 248.

Craig, T. (2007). Promoting understanding in mathematical problem-solving through writing: A Piagetian analysis. Unpublished doctoral thesis, University of Cape Town, South Africa.

De La Paz, S. (2005). Effects of historical reasoning instruction and writing strategy mastery in culturally and academically diverse classrooms. Journal of Educational Psychology, 97(2), 139-156.

Department of Education. (1997). Curriculum 2005. Pretoria: Department of Education. Retrieved on 28 November 2003 from http://www.policy.org.za/govdocs/misc/ curr2005.html.

Department of Education. (2000). Instructional leadership. School management teams. Pretoria: Department of Education.

Department of Education. (2005). Systemic evaluation intermediate phase teacher's guide. Mathematics. Pretoria: Department of Education.

Graven, M. (2002). Coping with new mathematics teacher roles in a contradictory context of curriculum change. The Mathematics Educator, 12(2), 21-27.

Haeck, W., Yeld, N., Conradie, J., Robertson, N., \& Shall, A. (1997). A developmental approach to mathematics testing for university admissions and course placement. Educational Studies in Mathematics, 33, 71-91.

Hoyles, C., Newman, K., \& Noss, R. (2001). Changing patterns of transition from school to university mathematics. International Journal of Mathematical Education in Science and Technology, 32(6), 829-845. 
Jacobs, M, Gawe, N \& Vakalisa, N. (2000). Teaching-learning dynamics: A participative approach to $O B E$. Johannesburg: Heinemann.

Jansen, J. D. (1998). Curriculum reform in South Africa: A critical analysis of outcomesbased education. Cambridge Journal of Education, 28(3), 321-331.

Kentucky Department of Education. (1995). Transformations: Kentucky's curriculum framework, Volume II. Frankfort: Author.

Lichakane, T. E. (2005). Teaching methods used by educators at Marquard sub-district: An OBE perspective. MEd dissertation, University of the Free State. Retrieved on 14 February 2007 from http: / / www.fsdoe.fs.gov.za/orginfo/research/teachingmethods.pdf.

Northedge, A. (2003). Rethinking teaching in the context of diversity. Teaching in Higher Education, 8(1), 17-32.

Owen, J. E. (1995). Cooperative learning in secondary schools. London: Routledge.

Revised National Curriculum Statement. (2002). Teacher's guide for development of learning programme: Policy naturals sciences. Grade R-9 (Schools). Pretoria: Department of Education.

Seymore, E. (2001). Tracking the processes of change in U. S. undergraduate education in science, mathematics, engineering, and technology. Science Education, 86, 79-105.

Wood, L. (2001). The secondary-tertiary interface. In D. Holton (Ed.) The teaching and learning of mathematics at university level, An ICMI study. Dordrecht, The Netherlands: Kluwer Academic Publishers.

Zevenbergen, R. (2001). Changing contexts in tertiary mathematics: Implications for diversity and equity. In D. Holton (Ed.) The teaching and learning of mathematics at university level, An ICMI study. Dordrecht, The Netherlands: Kluwer Academic Publishers.

\section{Authors}

Johann Engelbrecht, University of Pretoria, South Africa. Email: <jengelbr@up.ac.za>

Ansie Harding, University of Pretoria, South Africa. Email: <aharding@up.ac.za> 